\title{
Keys to the Trematoda. Volume 3 (Eds. R.A. Bray, D.I. Gibson and $A$. Jones) CABI Publishing, Wallingford, UK and the Natural History Museum, London, 2008, ISBN 978085199588 5, 824 pp.
}

This excellent book represents the final part of three volumes of keys to trematode parasites, a fundamental series on the systematics and identification of the class Trematoda.

The third volume covers five superfamilies within the order Plagiorchiida plus the family Didymozoidae, with keys for their identification at the family, subfamily and generic levels. In addition, it also includes a key to all the digenean superfamilies, including those treated in the two previous volumes. Those two volumes dealt with the subclass Aspidogastrea and the orders Strigeida and Echinostomida plus the first two superfamilies of the order Plagiorchiida. This volume of keys is, like its predecessors, based on a critical examination of specimens by specialists on each group. The generic diagnoses are updated and accompanied by excellent illustrations of the important morphological characters. The book is complemented with an extensive bibliography.

Authors of the present volume include the best specialists from the UK, USA, Australia, Brazil, France, India, Poland, Russia and the Czech Republic. The important feature of this series of keys is that it provides a stable classification based on morphological characters of adult trematodes, which enables the identification of all of the digenean groups. Both the editors and the authors of this volume have succeeded in preparing an essential book, which is of value to experts, practising parasitologists and beginners in this field; they should be congratulated on their success.
This excellent series will prove valuable not only as a fundamental reference book for parasitologists, both at professional and student levels, but also in the fields of medical, veterinary, wildlife and fisheries parasitology. These keys will, however, prove to be especially essential to parasitologists involved in the identification and research in medical and veterinary helminthology. They are an indispensable acquisition for every institutional library where such studies are carried out, either at present or anticipated in the future. The price for the hardback issue of the new volume, which will be in demand for many, many years, is $165 \mathrm{GBP}$.

Zdzisław Świderski W. Stefański Institute of Parasitology Polish Academy of Sciences Department of General Biology \& Parasitology Medical University of Warsaw; Poland

Boyko B. Georgiev Central Laboratory of General Ecology Bulgarian Academy of Sciences 2 Gagarin Street, 1113 Sofia, Bulgaria Department of Zoology, Natural History Museum Cromwell Road, London SW7 5BD; UK 